\title{
Adipose differentiation-related protein is not involved in hypoxia inducible factor-1-induced lipid accumulation under hypoxia
}

\author{
GUOMIN SHEN $^{1 *}$, NING NING $^{2 *}$, XINGSHENG ZHAO $^{3 *}$, XI LIU $^{3}$, GUANGYU WANG $^{4}$, TIANZHEN WANG $^{5}$, \\ RAN ZHAO $^{5}$, CHAO YANG $^{5}$, DONGMEI WANG ${ }^{1}$, PINGYUAN GONG $^{1}$, YAN SHEN ${ }^{1}$, YONGJIAN SUN ${ }^{1}$, \\ XIAO ZHAO ${ }^{1}$, YINJI JIN ${ }^{5}$, WEIWEI YANG ${ }^{5}$, YAN HE ${ }^{5}$, LEI ZHANG ${ }^{5}$, XIAOMING JIN ${ }^{5}$ and XIAOBO LI $^{5}$ \\ ${ }^{1}$ Department of Medical Genetics, Medical College, Henan University of Science and Technology, Luoyang, Henan 471003; \\ ${ }^{2}$ Department of Gastrointestinal Surgery, International Hospital of Peking University, Beijing 100871; \\ ${ }^{3}$ Department of Cardiovascular Disease, Inner Mongolia People's Hospital, Hohhot, Inner Mongolia 010070; \\ ${ }^{4}$ Department of Gastrointestinal Medical Oncology, The Affiliated Tumor Hospital of Harbin Medical University, Harbin, \\ Heilongjiang 100036; ${ }^{5}$ Department of Pathology, Harbin Medical University, Harbin, Heilongjiang 150086, P.R. China
}

Received December 29, 2014; Accepted September 25, 2015

DOI: $10.3892 / \mathrm{mmr} .2015 .4488$

\begin{abstract}
Increasing evidence has showed that hypoxia inducible factor-1 (HIF1) has an important role in hypoxia-induced lipid accumulation, a common feature of solid tumors; however, its role remains to be fully elucidated. Adipose differentiation-related protein (ADRP), a structural protein of lipid droplets, is found to be upregulated under hypoxic conditions. In the present study, an MCF7 breast cancer cell line was used to study the role of ADRP in hypoxia-induced lipid accumulation. It was demonstrated that hypoxia induced the gene expression of $A D R P$ in a HIF1-dependent manner. Increases in the mRNA and protein levels of ADRP was accompanied by increased HIF1A activity. In addition, a significant decrease in the mRNA and protein levels of ADRP were detected in presence of siRNA targeting HIFlA. Using a dual-luciferase reporting experiment and chromatin immunoprecipitation assay, the present study demonstrated that ADRP is a direct target gene of HIF1, and identified a functional hypoxia response element localized $33 \mathrm{bp}$ upstream of the transcriptional start site of the $A D R P$ gene. Furthermore, the present study demonstrated the role of ADRP in low density liporotein (LDL) and very-LDL uptake-induced lipid
\end{abstract}

Correspondence to: Dr Guomin Shen, Department of Medical Genetics, Medical College, Henan University of Science and Technology, 6 Anhui Road, Luoyang, Henan 471003, P.R. China E-mail: shenba433@163.com

Dr Xiaobo Li, Department of Pathology, Harbin Medical University, 157 Baojian Road, Harbin, Heilongjiang 150086, P.R. China

E-mail: lixiaobo@ems.hrbmu.edu.cn

${ }^{*}$ Contributed equally

Key words: adipose differentiation-related protein, hypoxia inducible factor-1, lipid accumulation, hypoxia accumulation under hypoxia. The knockdown of ADRP did not reduce HIF1-induced lipid accumulation under hypoxia. Together, these results showed that ADRP may be not involved in HIF1-induced lipid accumulation.

\section{Introduction}

Hypoxia inducible factor-1 (HIF1) has been identified for $\sim 20$ years (1) and is necessary to reprogram cellular metabolism, which is essential during physiological and pathological processes (2). HIF-1 regulates the transcription of hundreds of genes, which are involved in energy metabolism (3). The role of HIF1 in glucose metabolism has been well addressed. Previous investigations have suggested that HIF1 is also important in lipid metabolism, including regulating lipid uptake and trafficking, fatty acid metabolism, sterol metabolism, triacylglycerol synthesis and phospholipid metabolism, lipid droplet formation and lipid signaling (4-6).

Adipose differentiation-related protein (ADRP) is a structural protein in lipid droplets, which regulates lipid accumulation. Overexpression of the ADRP gene stimulates lipid accumulation in mouse fibroblasts (7) and in human macrophages (8), whereas knockdown of the ADRP gene reduces the level of triglycerides and esterified cholesterol in THP-1 macrophages (8). In addition, in a mouse model, inactivation of ADRP gene results in a significant reduction in lipid droplet accumulation following overnight incubation with oxidized low density lipoprotein (oxLDL) (9). These results suggest that ADRP facilitates lipid accumulation.

It has been reported that the expression of ADRP increases under hypoxic conditions (10-12). However, whether ADRP is a direct target gene of HIF1 is unknown. In a previous study, lipid accumulation was observed in human breast cancer and it was identified that enhancement of LDL and VLDL uptake induced by HIF1 under hypoxia contributes to lipid accumulation in the breast cancer cell line MCF7 (13). However, whether ADRP is also involved in lipid accumulation and the uptake of LDL and VLDL under hypoxia in breast cancer, remains 
to be elucidated. In the present study, a dual luciferase assay and chromatin immunoprecipitation (ChIP) experiment was performed to determine the presence of a functional hypoxia response element (HRE) in the ADRP gene promoter and determine whether ADRP is a direct target gene of HIF1. The results of our previous study showed that hypoxia promoted LDL and very-(V)LDL uptake, in an HIF1-dependent manner, thus the present study investigated the role of ADRP in LDL and VLDL uptake and lipid accumulation under hypoxia.

\section{Materials and methods}

Cell culture, hypoxic exposure, DFO, LDL and VLDL treatment. MCF7, a breast cancer cell line used for investigating the role of hypoxia in lipid accumulation in a previous study (13), was purchased from the Cell Center of the Institute of Basic Medical Science, Chinese Academy of Medical Sciences (Beijing, China). MCF7 cells $\left(1 \times 10^{6}\right)$ were grown in Dulbecco's modified Eagle's medium (DMEM; Gibco; Thermo Fisher Scientific, Inc., Waltham, MA, USA) supplemented with $10 \%$ fetal bovine serum (FBS), $100 \mathrm{U} / \mathrm{ml}$ penicillin and $100 \mu \mathrm{g} / \mathrm{ml}$ streptomycin (all from Gibco; Thermo Fisher Scientific, Inc.). Cells incubated in normoxic cells were maintained at $37^{\circ} \mathrm{C}$ in a $5 \% \mathrm{CO}_{2}$ and $95 \%$ air incubator. The cells exposed to hypoxia were placed in a three gas incubator (YCP-50S; Huaxi Electronic Technologies, Changsha, China) with $5 \% \mathrm{CO}_{2}$, $94 \% \mathrm{~N}_{2}$ and $1 \% \mathrm{O}_{2}$ at $37^{\circ} \mathrm{C}$. The cells reached $70 \%$ confluence prior to treatment with DFO, LDL or VLDL. For DFO treatment, $100 \mu \mathrm{M}$ DFO (Sigma-Aldrich, St. Louis, MO, USA) was added to the culture medium for $24 \mathrm{~h}$. For LDL treatment, the culture medium was replaced with fresh medium (10\% FBS) with, or without, LDL at a final concentration of $200 \mu \mathrm{g} / \mathrm{ml}$. For VLDL treatment, the culture medium was replaced with fresh medium (10\% FBS), with or without, VLDL at a final concentration of $100 \mu \mathrm{g} / \mathrm{ml}$. The cells were placed in either normoxic or hypoxic incubators, cultured for $24 \mathrm{~h}$, and then fixed with formaldehyde (Sigma-Aldrich, St. Louis, MO, USA) and recollected for analysis. Human LDL and VLDL were purchased from Peking Union Bio Co., Ltd. (Beijing, China).

Plasmid construction. The promoter region of the ADFP gene was amplified from human genomic DNA using polymerase chain reaction (PCR) and cloned into a luciferase reporter vector (pGL3-Basic; Promega Corporation, Madison, WI, USA). Briefly, human genomic DNA was extracted using a Quick Genomic DNA Extraction kit (Guangzhou Dongsheng Biotech Co., Ltd., Guangzhou, China) according to manufacturer's instructions. A total of $50 \mathrm{ng}$ genomic DNA was then used as a template to amplify the promoter region of the ADFP gene in $20 \mu \mathrm{l}$ reaction system containing $1 \mu \mathrm{l}$ of $10 \mu \mathrm{M}$ primers (Sangon Biotech Co., Ltd. Shanghai, China), $1 \mu \mathrm{l}$ of $25 \mu \mathrm{M}$ dNTP mixture (Beijing TransGen Biotech Co., Ltd., Beijing, China) and $1 \mu$ l DNA polymerase (Beijing TransGen Biotech Co., Ltd.). The following primer sequences were used: ADFP, forward 5'-agacgcgtCATGCCTGGCTATTTAGTG-3' and reverse 5'-ccctcgagCTCATGCCGGTAATCCCAGCA-3'. The PCR reaction was performed in a PCR Thermocycler (Thermo Fisher Scientific, Inc.) with the following reaction conditions: $95^{\circ} \mathrm{C}$ for $5 \mathrm{~min}$, followed by 40 cycles of $95^{\circ} \mathrm{C}$ for $30 \mathrm{sec}$, $60^{\circ} \mathrm{C}$ for $30 \mathrm{sec}$ and $72^{\circ} \mathrm{C}$ for $1 \mathrm{~min}$. As a positive control, the nucleotide sequence containing the identified HRE of the erythropoietin (EPO) gene (14) was also cloned into the pGL3-promoter.

Western blotting. Total protein was extracted from the tissue samples or cells using lysis buffer (Beyotime Institute of Biotechnology, Shanghai, China), and subsequently quantified using the Bradford method (Bio-Rad Laboratories, Inc., Hercules, CA, USA). A total of $20 \mu \mathrm{g}$ protein was separated by 10\% SDS-PAGE (Bio-Rad Laboratories, Inc., Hercules, CA, USA) and transferred onto a polyvinylidene fluoride membrane (Bio-Rad Laboratories, Inc.). Following blocking with $1 \%$ bovine serum albumin (Sigma-Aldrich), the membrane was incubated with primary antibodies overnight at $4^{\circ} \mathrm{C}$, then washed with Tris-buffered saline with $0.1 \%$ Tween 20 buffer (TBST; Beyotime Institute of Biotechnology) at room temperature, prior to incubation with secondary antibody for $1 \mathrm{~h}$ at room temperature. Following washing with TBST buffer, the signals were detected using an Electrochemiluminescence kit (EMD Millipore, Billerica, MA, USA) and analyzed with ImageJ version 1.41o (National Institutes of Health, Bethesda, MD, USA). The antibodies used in the present study included: Mouse anti-human HIF-1 $\alpha$ monoclonal antibody (dilution 1:500; cat. no. sc-13515; Santa Cruz Biotechnology, Inc., Dallas, TX, USA), rabbit anti-human $\beta$-actin monoclonal antibody (dilution 1:1000; cat. no. sc-1616-R; Santa Cruz Biotechnology, Inc.), rabbit anti-human ADRP polyclonal antibody (dilution 1:500; cat. no. ab78920; Abcam, Cambridge, MA, USA), and horseradish peroxidase-conjugated goat anti-mouse (dilution 1:10,000; cat. no. sc-2005; Santa Cruz Biotechnology, Inc.) and goat anti-rabbit (dilution 1:10,000; cat. no. sc-2004; Santa Cruz Biotechnology, Inc.) secondary antibody.

Transient transfection and luciferase assay. The MCF7 cells were plated at a density of $1 \times 10^{5}$ cells into 24 -well plates to reach $\sim 50-70 \%$ confluence the following day. The cells were co-transfected with the pGL3-basic-based construct and pRL-TK plasmid DNAs using Lipofectamine Plus (Invitrogen; Thermo Fisher Scientific, Inc.). The transfection medium was replaced with complete medium after $6 \mathrm{~h}$. The cells were incubated in normoxia or hypoxia for an additional $24 \mathrm{~h}$. Following incubation, the cells were lysed and reporter gene expression was assessed using a dual-luciferase reporter assay system (Promega Corporation). The cells were lysed and reporter gene expression was assessed using a Dual Luciferase ${ }^{\circledR}$ Reporter Assay system (Promega Corporation) according to manufacturer's instructions. Briefly, the cells were lysed with passive lysis buffer (Promega Corporation) at room temperature, the firefly and Renilla luciferase activities of the lysates were determined, and the firefly luciferase activity levels were normalized to that of Renilla luciferase.

RNA isolation and PCR analysis. The cells were dissolved in TRIzol reagent (Invitrogen; Thermo Fisher Scientific, Inc.), and total RNA was extracted, according to the manufacturer's protocol. Total RNA ( $1 \mu \mathrm{g})$ was converted into $1 \mu \mathrm{g}$ cDNA using an M-MLV reverse-transcription system (Invitrogen; Thermo Fisher Scientific, Inc.) in the presence of oligo $(\mathrm{dT})_{18}$ (Beijing TransGen Biotech Co., Ltd.). Reverse transcription-quantitative (RT-q)PCR was performed using an ABI-7500 Fast Sequence 
Detection system (Applied Biosystems; Thermo Fisher Scientific, Inc.) with SYBR ${ }^{\circledR}$ Green PCR mix (Beijing TransGen Biotech Co., Ltd.). The reaction system contained $10 \mu 1$ 2X SYBR ${ }^{\circledR}$ Green PCR Master mix (Beijing TransGen Biotech Co., Ltd.), 4 pmol of each primer (Sangon Biotech Co., Ltd.) and $0.2 \mu \mathrm{l}$ RT reaction product. The samples were set in triplicate. The thermocycling parameters were as follows: $95^{\circ} \mathrm{C}$ for $10 \mathrm{~min}$, followed by 40 cycles of $95^{\circ} \mathrm{C}$ for $15 \mathrm{sec}$ and $60^{\circ} \mathrm{C}$ for $30 \mathrm{sec}$, and a detection step at $72^{\circ} \mathrm{C}$ for $30 \mathrm{sec}$. The specific gene primers were as follows: HIF-1 $\alpha$ forward, 5'-AGG TGG ATA TGT CTG GGTTG-3', HIF-1 $\alpha$ reverse, 5'-AAG GAC ACA TTC TGT TTG TTG-3'; ADRP forward, 5'-GGC TAG ACA GGA TTG AGG AGAG-3', and ADRP reverse, 5'-TCA CTG CCC CTT TGG TCTTG-3'. The relative abundance of the HIF-1 $\alpha$ and ADRP transcript was quantified using the comparative Cq method (15), with $\beta$-actin as an internal control.

ChIP assay. The MCF7 cells were plated $\left(2 \times 10^{6}\right)$ into a $15 \mathrm{~cm}$ plate and grown to $\sim 70 \%$ confluence. Then the cells were exposed to hypoxia for $24 \mathrm{~h}$, and a ChIP assay was performed, as previously described (16). Briefly, the cells were fixed with $1 \%(\mathrm{v} / \mathrm{v})$ formaldehyde (Sigma-Aldrich) for $10 \mathrm{~min}$ at room temperature. Crosslinking was blocked by the addition of $0.125 \mathrm{M}$ glycine (Sigma-Aldrich) for $5 \mathrm{~min}$ at room temperature. The cells were then washed with ice-cold phosphate-buffered saline (PBS) and resuspended in cell lysis buffer provided in the EZ-Magna ChIP kit (cat. no. 17-409; EMD Millipore). The lysates were centrifuged at 10,000 x g at $4^{\circ} \mathrm{C}$ and the pellets were resuspended in nuclear lysis buffer provided in the EZ-Magna ChIP kit (EMD Millipore). The nuclear lysates were sonicated for chromatin fraction. The chromatin fraction was immunoprecipitated overnight at $4^{\circ} \mathrm{C}$ with $5 \mu \mathrm{g}$ rabbit anti-human HIF-1 $\alpha$ polyclonal antibody (cat. no. ab2185; Abcam) and $5 \mu \mathrm{g}$ rabbit anti-human IgG polyclonal antibody (cat. no. ab2410; Abcam) respectively. The precipitated DNA was amplified by PCR with the following primers: P1, 5'-ACTCGGGCTTGGGACAGGGC-3'; P2, 5'-GCGAAAGGCGAAGAGCAGGCG-3'; P3, 5'-TGACATCAAGCAGTCCACCC-3'; and P4, 5'-CTCAGGAGGGAGAAGTAAAGTTG-3'. PCR reactions were performed in a $20 \mu \mathrm{l}$ system containing $1 \mu \mathrm{l}$ of $10 \mu \mathrm{M}$ primers (Sangon Biotech Co., Ltd.), $1 \mu \mathrm{l}$ of $25 \mu \mathrm{M}$ dNTP mixture (Beijing TransGen Biotech Co., Ltd.) and $1 \mu \mathrm{l}$ DNA polymerase (Beijing TransGen Biotech Co., Ltd.) for 30 cycles consisting of denaturing for $10 \mathrm{sec}$ at $94^{\circ} \mathrm{C}$, annealing for $30 \mathrm{sec}$ at $58^{\circ} \mathrm{C}$ and extension for $1 \mathrm{~min}$ at $72^{\circ} \mathrm{C}$. As a positive control, the protein phosphatase 1 , regulatory subunit 3C (PPP1R3C) promoter region, which contained a known HIF-1 binding site, was amplified using primers as previously described (17).

Cell transfection with small interfering (si)RNA. At 1 day prior to transfection, the cells were plated $\left(5 \times 10^{5}\right)$ into 6 -well plates. The cells were grown to $50 \%$ confluence and then transfected with $25 \mathrm{nM}$ (final concentration) of siGENOME non-targeting siRNA2, human HIF1A, siGENOME SMART pool, or human ADRP siGENOME SMART pool (Thermo Fisher Scientific, Inc.) using Dharma FECT1 transfection reagent, according to the manufacturer's protocol (Thermo Fisher Scientific, Inc.). Following $24 \mathrm{~h}$ incubation in normoxic conditions, the trans-
A

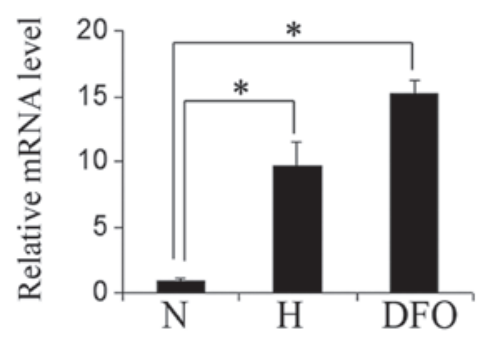

B

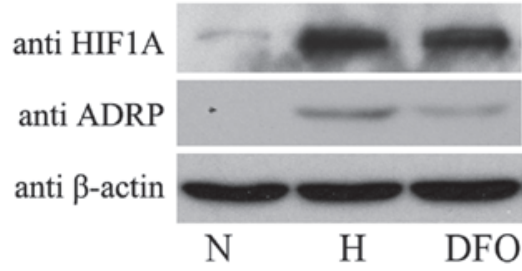

C

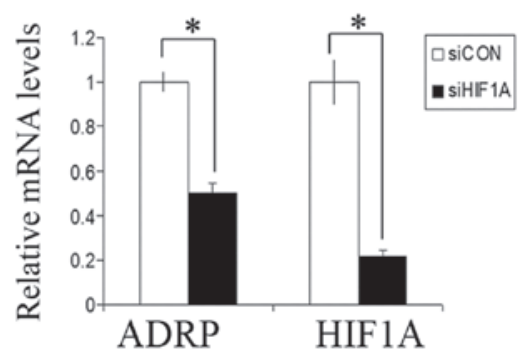

D

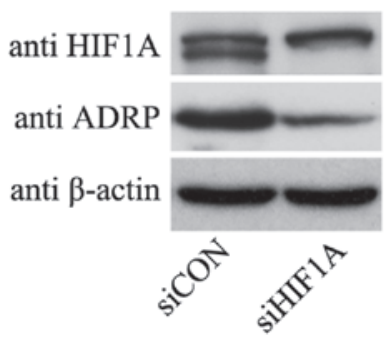

Figure 1. ADRP is induced by hypoxia in an HIF-dependent manner (A) mRNA levels of ADRP were analyzed using qPCR in MCF7 cells cultured in normoxia or hypoxia, or in medium containing $100 \mu \mathrm{M}$ DFO for $24 \mathrm{~h}$ The mRNA levels of ADRP were normalized to those of $\beta$-actin. The relative mRNA expression of ADRP is presented as the values in hypoxia, relative to normoxia. Data are expressed as the mean \pm standard deviation.(B) Protein levels of HIF1 $\alpha$, ADRP and $\beta$-actin in the MCF7 cells were determined using western blotting under the different treatment conditions. Anti- $\beta$-actin antibody was used as a control for equal protein loading. (C) mRNA levels of ADRP and HIF1 $\alpha$ were determined using qPCR in MCF7 cells transfected with siHIF1A and siCON. The relative mRNA expression levels are presented as the fold values of mRNA levels in cells transfected with siHIF1A/cells transfected with siCON. Data are expressed as the mean \pm standard deviation (D) Protein levels of HIF1 $\alpha$, ADRP and $\beta$-actin in the transfected MCF7 cells were determined using western blot assays, as above. ${ }^{*} \mathrm{P}<0.05$. ADRP, Adipose differentiation-related protein; HIF1, hypoxia-inducible factor-1; N, normoxia; H, hypoxia; DFO, deferoxamine mesylate salt; si, small interfering RNA; CON, control.

fection medium was replaced with complete medium, and the cells were incubated in hypoxic conditions for another $24 \mathrm{~h}$. The total RNA and cell lysates were collected for qPCR and western blotting, respectively. 
A

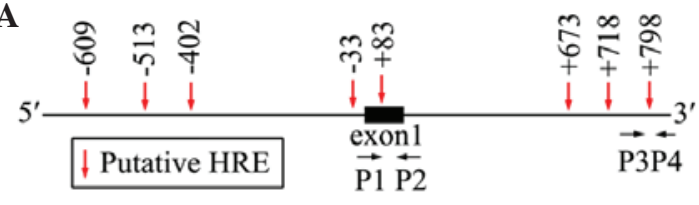

C

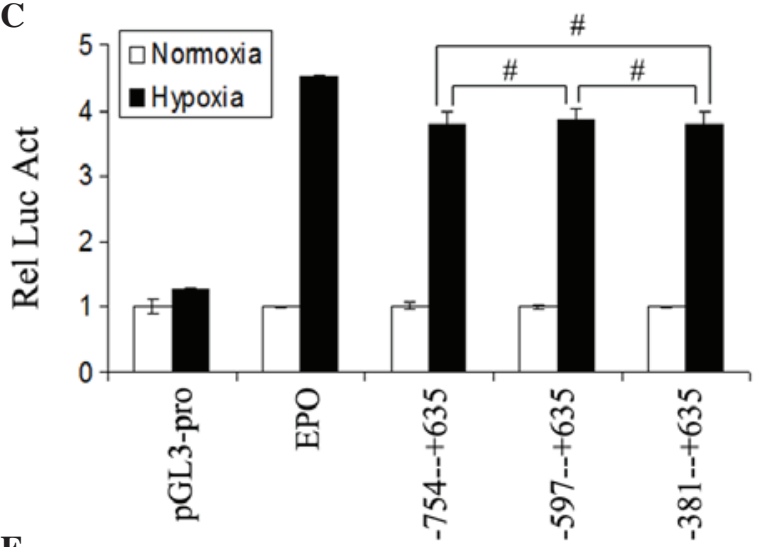

$\mathbf{E}$

B $\begin{array}{ll}-47 \text { 5'-AGGGCGCCGGGACGTGCCCGAGG-3' -25 } & \text { Human } \\ -751 \text { 5'-AGAGGGCAGGGACGTGAACTGGG-3' -775 } & \text { Mouse } \\ -871 \text { 5'-AGAACGCAGGGACGTGAACTGGG-3' -893 } & \text { Rat } \\ \text { RCGTG } & \end{array}$

D

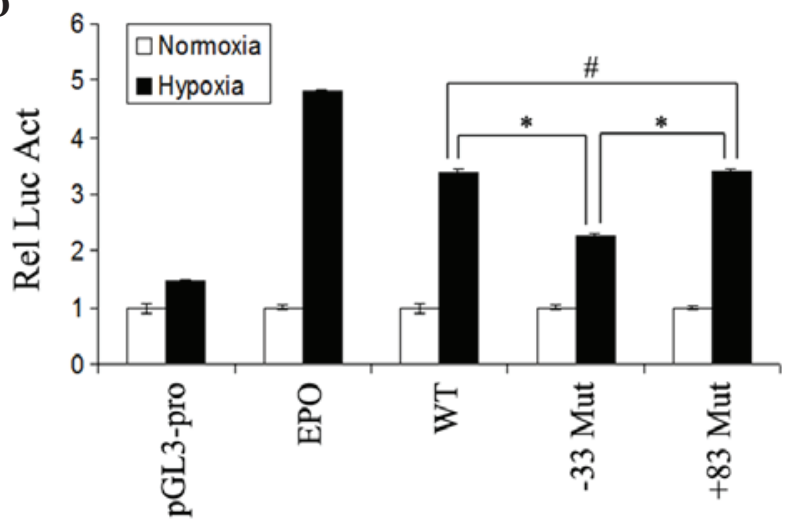

$\mathbf{F}$

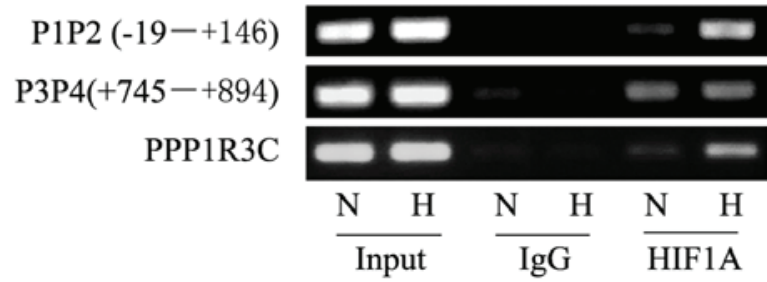

Figure 2. Identification and validation of HREs in the ADRP gene promoter. (A) Sketch map of the ADRP promoter region. The putative HREs are indicated by arrows. The nucleotide sequences are numbered in relation to the transcription initiation site, which is designated ' +1 '. $\mathrm{P} 1, \mathrm{P} 2, \mathrm{P} 3$ and $\mathrm{P} 4$ indicate the primers used for polmterase chain reaction amplification of the immunoprecipitated chromatin fragments in Fig. 2E. (B) Comparison of the conserved HRE and flanking nucleotides identified in the human, rat and mouse ADRP gene promoter regions. (C and D) Luciferase reporter assays were performed in MCF7 cells transfected with the constructs containing the indicated sequences from the human ADRP gene promoter region. Each transfection experiment was performed in triplicate. The relative mean luciferase activity in the cells under hypoxia is shown as the fold over the mean activity in the cells under normoxia. Error bars represent the mean \pm standard deviation. pGL3-pro and EPO represent negative and positive control, respectively. (E) Mutant sequence of the putative HREs in the construct of Fig. 2D are indicated. (F) ChIP-PCR assays were performed using the indicated primers and antibodies, to demonstrate binding of HIF1 $\alpha$ to the -33 HRE of ADRP in the MCF7 cells under normoxic and hypoxic conditions. PPP1R3C was used as a positive control. ADRP, adipose differentiation-related protein; HIF1, hypoxia-inducible factor-1; N, normoxiaa; H, hypoxia; HRE, hypoxia response element; EPO, erythropoietin; WT, wild-type; Mut, mutant; PPP1R3C, protein phosphatase 1, regulatory subunit 3C; Rel Luc Act, relative luciferase activity. "P<0.05 and ${ }^{" ~} \mathrm{P}>0.05$.

Flow cytometric analysis. The cells were plated $\left(5 \times 10^{5}\right)$ into 6 -well plate. Following incubation and treatment, the cells were digested with $0.25 \%$ trypsin-EDTA (Gibco; Thermo Fisher Scientific, Inc.), collected and washed with PBS three times at room temperature. Subsequently, the cells were fixed with $3.7 \%$ formaldehyde (Sigma-Aldrich) for $30 \mathrm{~min}$ at room temperature. The cells were then rinsed immediately with PBS twice at room temperature, following which the cells were stained with $1 \mathrm{ml}$ Nile Red working solution for $20 \mathrm{~min}$ at $37^{\circ} \mathrm{C}$. The cells were then rinsed with PBS twice at room temperature, resuspended in PBS and analyzed immediately using an Accuri C6 flow cytometer system (Accuri cytometers, Ann Arbor, MI, USA). The Nile Red stock solution was purchased from Genmed Scientifics (Arlington, MA, USA), and was prepared by diluting $0.5 \mu \mathrm{l}$ of the stock solution in $1 \mathrm{ml}$ PBS, and mixing well.

Intracellular lipid qualification. The $1 \times 10^{5}$ MCF7 cells were plated into 24-well plate following incubation and treatment, and intracellular lipid quantification was performed using a
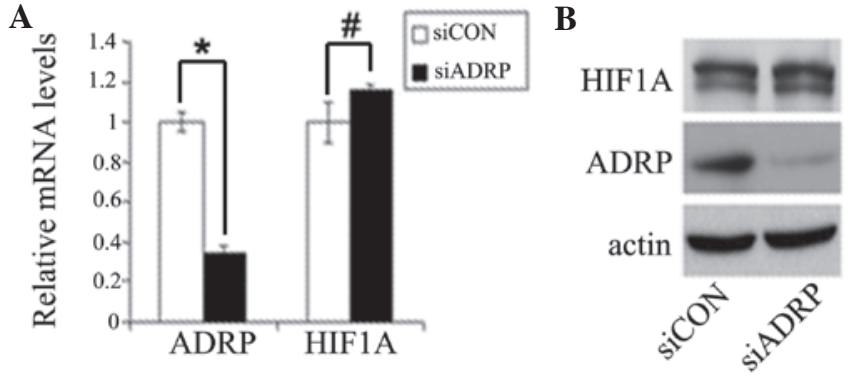

Figure 3. Detection and validation of $A D R P$ knockdown. (A) mRNA levels of ADRP and HIF1A were determined using qPCR. The mRNA levels of ADRP and HIF1 $\alpha$ were normalized to those of $\beta$-actin. The relative expression level of each mRNA is presented as the fold values in cells transfected with siADRP/siCON. Data are presented as the mean \pm standard deviation of three independent experiments. (B) Protein levels of ADRP, HIF1A and $\beta$-actin were determined using western blot assays. $\beta$-actin was used as a loading control. ${ }^{*} \mathrm{P}<0.05$ and ${ }^{\text {}} \mathrm{P}>0.05$. ADRP, adipose differentiation-related protein; HIF1, hypoxia-inducible factor-1; si, small interfering RNA; CON, control.

Steatosis Colorimetric Assay kit (cat. no. 10012643-1; Cayman Chemical Co., Ann Arbor, MI, USA) according to the manu- 


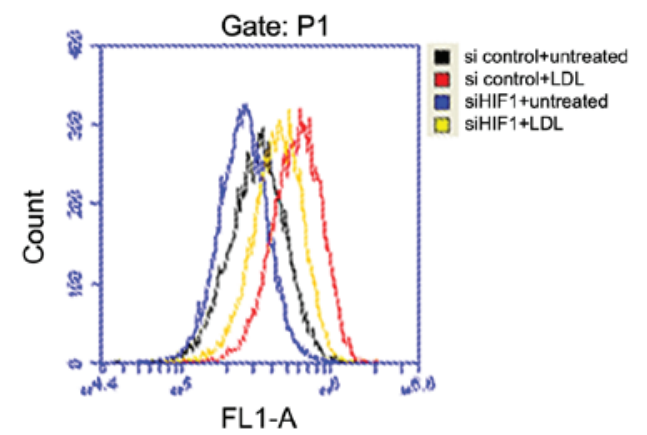

C

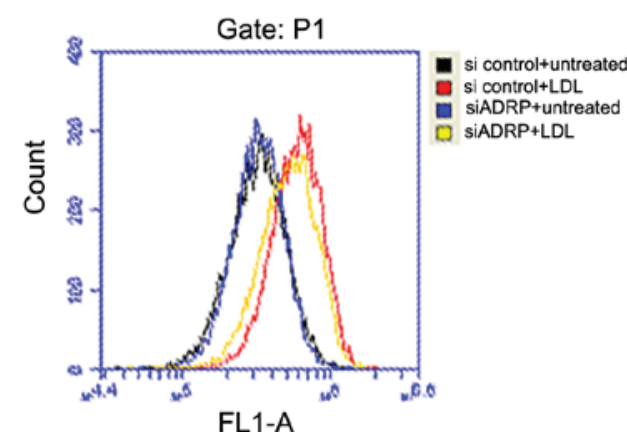

B

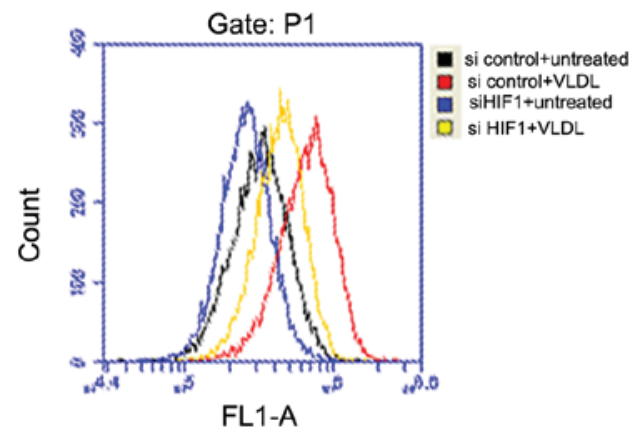

D

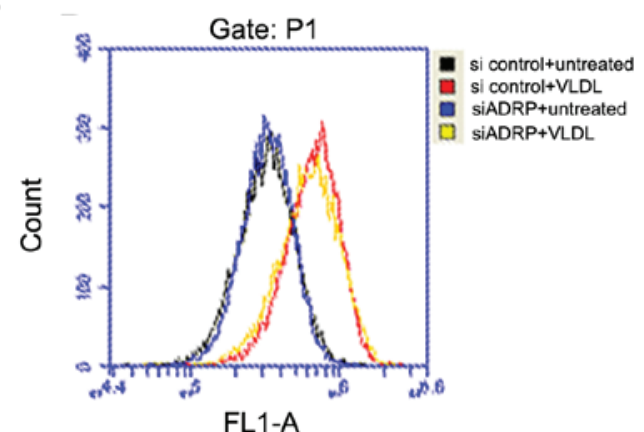

E

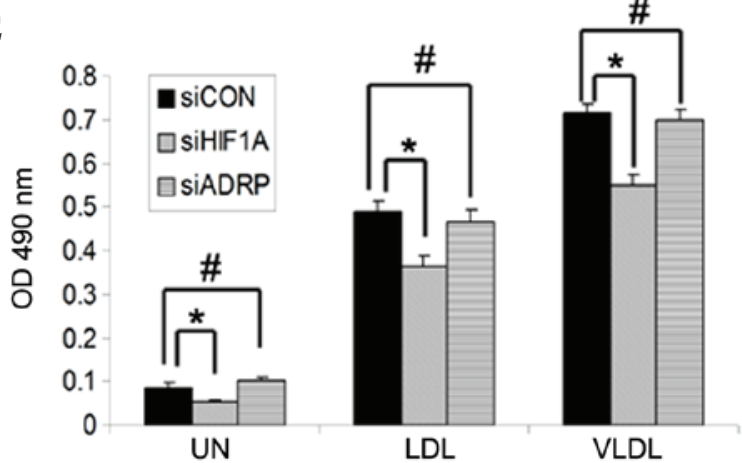

Figure 4. ADRP does not affect LDL and VLDL uptake or lipid accumulation under hypoxia. MCF7 cells were transfected with siHIF1 $\alpha$ or siCON for 24 h, following which the cells were treated with (A) LDL or (B) VLDL and incubated under hypoxia for an additional 24 h. MCF7 cells were transfected with siADRP or siCON for $24 \mathrm{~h}$, following which the cells were treated with (C) LDL or (D) VLDL and incubated under hypoxia for an additional $24 \mathrm{~h}$. Cells $\left(5 \times 10^{4}\right)$ were stained with Nile Red, and flow cytometry was used to measure intracellular lipid levels by detecting the value of OD575. (E) MCF7 cells were transfected with siRNAs and treated with LDL or VLDL, followed by incubation under hypoxia. Intracellular lipid content was measured using a steatosis colorimetric assay kit. Data are presented as the mean \pm standard deviation. ADRP, adipose differentiation-related protein; HIF1, hypoxia-inducible factor-1; LDL, low density lipoprotein; VLDL, very-LDL; si, small interfering RNA; CON, control; UN, untreated; OD, optical density. *P<0.05 and "P>0.05.

facture's protocol. Briefly, the cells were fixed with $1 \%(\mathrm{v} / \mathrm{v})$ formaldehyde (Sigma-Aldrich) for $15 \mathrm{~min}$ at room temperature, washed twice with PBS (Thermo Fisher Scientific, Inc.) at room temperature for $5 \mathrm{~min}$ each, following which the well was dried completely and Oil Red O (Cayman Chemical Co.) working solution added to all cells, and incubated for $20 \mathrm{~min}$ at room temperature. The cells were washed with distilled water five times at room temperature for $5 \mathrm{~min}$, and the cells were dried completely. Finally, dye extraction solution (Cayman Chemical Co.) was added to each well, gently mixed for $30 \mathrm{~min}$ at room temperature, and the absorbance was measured at $490 \mathrm{~nm}$ with a microplate reader (BioTek Instruments Inc., Winooski, VT, USA).

Statistical analysis. The data were presented as the mean \pm standard deviation, and subjected to one-way analysis of variance. Student's t test was used to compare the relative expression levels of target genes and the relative quantity of cellular lipid. The SPSS version 10.0 software package for Windows (SPSS, Inc., Chicago, IL, USA) was used for statistical analysis. $\mathrm{P}<0.05$ was considered to indicate a statistically significant result.

\section{Results}

Hypoxia induces ADRP in an HIFl-dependent manner. To examine whether the gene expression of $A D R P$ was oxygen regulated, the MCF7 cells were incubated under normoxic $\left(21 \% \mathrm{O}_{2}\right)$ or hypoxic $\left(1 \% \mathrm{O}_{2}\right)$ conditions, or in medium containing $100 \mu \mathrm{M}$ deferoxamine mesylate salt (DFO) for $24 \mathrm{~h}$. Subsequent qPCR assays (Fig. 1A) revealed an increase in the mRNA levels of ADRP in the cells under hypoxic conditions or following DFO treatment. The protein levels of ADRP in the MCF7 cells were determined using immunoblotting 
(Fig. 1B). Increased protein levels of ADRP were observed with increasing protein levels of HIF1A in the cells under hypoxic conditions or following DFO treatment. These results indicated $A D R P$ as a hypoxia-inducible gene. In agreement, a significant decrease in the mRNA and protein levels of ADRP (Fig. 1C and D) were detected in the MCF7 cells transfected with siRNA targeting $H I F 1 A$, which suggested that inhibition of the HIF1A gene reduced the hypoxic induction of $A D R P$. Taken together, these results demonstrated that hypoxia induced the expression of $A D R P$ in a HIF1-dependent manner.

Identification and validation of HRE in the human ADRP gene. To determine whether ADRP was a direct target of HIF1 under hypoxia, the present study examined the promoter region of the human ADRP gene for a consensus HRE sequence, as previously described (3). Several putative HREs were identified (Fig. 2A), however, only the HRE at -33 in position is conserved in human, mouse and rat (Fig. 2B). To determine whether this was a functional HRE, the promoter region of the $A D R P$ gene was amplifed and inserted it into the luciferase reporter plasmid, pGL3-promoter. The plasmid of the pGL3-promoter was used as a negative control. A construct of the pGL3-promoter with the insertion of the identified HRE of the EPO gene was used as a positive control. As shown in Fig. 2C, the region between -754 and +635 markedly increased luciferase activity in the MCF7 cells under hypoxia. Analysis of the deletion constructs suggested that the conserved HRE was functional (Fig. 2C). Mutation of the conserved HRE significantly impaired the induction of luciferase activity by hypoxia, however, mutation of the putative HRE in exon 1 did not impair the luciferase activity by hypoxia (Fig. 2D and E), which also suggested that the conserved HRE may be a functional HRE.

To determine whether HIF1 binds to the conserved HRE within living cells, the present study performed ChIP assays using antibodies against HIF1A (IgG as a negative control) in the normoxic- and hypoxic-cultured MCF7 cells. The sequence containing the potential functional HRE in the $A D R P$ gene promoter was detected, and hypoxia significantly increased HIF1A binding to the HRE (Fig. 2F). The sequence containing the binding site of HIF1 in the known HIF1 target gene $P P P 1 R 3 C$, served as a positive control (17). The sequence between +745 and +894 in the ADRP promoter was detected, with primers P3 and P4 used as a negative control (Fig. 2F). Taken together, these results demonstrated that ADRP was a direct target of HIF1 under hypoxia.

ADRP is not important in hypoxia mediated $L D L$ and VLDL uptake or lipid accumulation. Our previous study demonstrated that hypoxia significantly increases LDL and VLDL uptake, and enhances lipid accumulation in MCF7 cells (13), and another investigation demonstrated that ADRP also promotes lipid accumulation following overnight incubation with oxLDL (9). Therefore, the present study aimed to determine whether ADRP induced by HIF1 also contributes to lipid accumulation under hypoxia. To investigate this, the MCF7 cells were transfected with ADRP siRNA and treated with LDL or VLDL, followed by exposure to normoxia or hypoxia for $24 \mathrm{~h}$. Reductions in the mRNA and protein levels of ADRP were observed in the cells transfected with the specific siRNA targeting $A D R P$ (Fig. 3A and B). Flow cytometry and a steatosis colorimetric assay kit were used to analyze intracellular lipid content. Consistent with our previous findings, the results showed that hypoxia induced lipid accumulation and LDL/VLDL uptake, in an HIF1-dependent manner (Fig. 4A and B). However, compared with the cells transfected with non-targeting siRNA (control), knockdown of ADRP did not reduce hypoxia-induced LDL and VLDL uptake or lipid accumulation (Fig. 4C-E). These results suggested that HIF1 promoted LDL and VLDL uptake, and lipid accumulation, but not through the induction of ADRP under hypoxia.

\section{Discussion}

ADRP is a structural protein of lipid droplets and it has been reported that ADRP is expressed at high levels and is associated with lipid accumulation in solid tumors, particularly in clear cell lesions $(18,19)$. In step-wise carcinogenesis, the expression of ADRP is correlated with the proliferation rate and is upregulated during early tumorigenesis (18). The expression of ADRP is also associated with atherosclerosis (9). It has been reported that ADRP is induced under hypoxic conditions in several studies (10-12), however, whether ADRP is a direct HIF1 target gene remains to be elucidated. Thus, the present study examined whether ADRP is a direct target gene of HIF1. The present study demonstrated that ADRP was a HIF1 direct target gene, and identified a functional HRE in the ADRP gene promoter; results which are consistent with previous reports (10-12).

It has been reported that hypoxia significantly increases LDL and VLDL uptake, and enhances lipid accumulation in arterial SMCs $(20-22)$, cardiomyocytes $(23,24)$ and cancer cell lines (13). As ADRP promotes lipid accumulation and is upregulated under hypoxic conditions, the present study investigated whether ADRP also contributes to lipid accumulation under hypoxic conditions. The presents study examined the impact of ADRP on LDL and VLDL uptake, and lipid accumulation under hypoxia. However, ADRP did not affect HIF1-mediated LDL and VLDL uptake or lipid accumulation under hypoxic conditions in the MCF7 cells. These data are not consistent with previous investigations, and the different experimental conditions may offer an explanation for the different results. The previous study was performed under normoxic conditions and used ox-LDL to incubate cells (9). In the present study, the cells were treated with LDL and VLDL under hypoxic conditions. In addition, lipid uptake and storage are two separate process. Several proteins are involved in lipid storage. Hypoxia-inducible protein 2 (HIG2), a novel protein identified as being associated with lipid droplets, is upregulated by hypoxia and is a direct and specific target of HIF1. Normoxic overexpression of HIG2 is sufficient to increase lipid droplets in HeLa cells (25). When knocking down ADRP, other HIF1 target genes involving lipid storage, including HIG2, may compensate the function of ADRP. The combined knockdown of these genes may affect HIF1-mediated LDL and VLDL uptake, and lipid accumulation. Therfore, further investigations are required to identify the genes, which are involved in lipid storage and are regulated by HIF1 under hypoxic conditions. 


\section{Acknowledgements}

This study was supported by the National Natural Science Foundation of China (grant. nos. 31301076, 81201688 and 81401961 to Dr Guomin Shen, Dr Ning Ning and Dr Xiaobo Li, respectively), the Science and Technology Plan Foundation of Inner Mongolia Autonomous Region (grant. no. 20130404 to Dr Xingsheng Zhao), the Hospital Foundation of Inner Mongolia Autonomous Region People's Hospital (grant. no. 201301 to Dr Xi Liu) and the Wu-Lian-De Youth Science Foundation of Harbin Medical University (grant. no. WLD-QN1411 to Dr Xiaobo Li) and the Postdoctoral Scientific Research Development Fund of Heilongjiang Province (grant no. LBH-Q14104 to Dr Xiaobo Li).

\section{References}

1. Wang GL, Jiang BH, Rue EA and Semenza GL: Hypoxia-inducible factor 1 is a basic-helix-loop-helix-PAS heterodimer regulated by cellular $\mathrm{O} 2$ tension. Proc Natl Acad Sci USA 92: 5510-5514, 1995.

2. Semenza GL: Hypoxia-inducible factors in physiology and medicine. Cell 148: 399-408, 2012.

3. Semenza GL: Defining the role of hypoxia-inducible factor 1 in cancer biology and therapeutics. Oncogene 29: 625-634, 2010 .

4. Scarfo LM, Weller PF and Farber HW: Induction of endothelial cell cytoplasmic lipid bodies during hypoxia. Am J Physiol Heart Circ Physiol 280: H294-H301, 2001.

5. Belanger AJ, Luo Z, Vincent KA, Akita GY, Cheng SH, Gregory RJ and Jiang C: Hypoxia-inducible factor 1 mediates hypoxia-induced cardiomyocyte lipid accumulation by reducing the DNA binding activity of peroxisome proliferator-activated receptor alpha/retinoid $\mathrm{X}$ receptor. Biochem Biophys Res Commun 364: 567-572, 2007.

6. Chabowski A, Gorski J, Calles-Escandon J, Tandon NN and Bonen A: Hypoxia-induced fatty acid transporter translocation increases fatty acid transport and contributes to lipid accumulation in the heart. FEBS Lett 580: 3617-3623, 2006.

7. Imamura M, Inoguchi T, Ikuyama S, Taniguchi S, Kobayashi K, Nakashima $\mathrm{N}$ and Nawata $\mathrm{H}$ : ADRP stimulates lipid accumulation and lipid droplet formation in murine fibroblasts. Am J Physiol Endocrinol Metab 283: E775-E783, 2002.

8. Larigauderie G, Furman C, Jaye M, Lasselin C, Copin C, Fruchart JC, Castro G and Rouis M: Adipophilin enhances lipid accumulation and prevents lipid efflux from THP-1 macrophages: Potential role in atherogenesis. Arterioscler Thromb Vasc Biol 24: 504-510, 2004.

9. Paul A, Chang BH, Li L, Yechoor VK and Chan L: Deficiency of adipose differentiation-related protein impairs foam cell formation and protects against atherosclerosis. Circ Res 102: 1492-1501, 2008.

10. Saarikoski ST, Rivera SP and Hankinson O: Mitogen-inducible gene 6 (MIG-6), adipophilin and tuftelin are inducible by hypoxia. FEBS Lett 530: 186-190, 2002.

11. Xia X, Lemieux ME, Li W, Carroll JS, Brown M, Liu XS and Kung AL: Integrative analysis of HIF binding and transactivation reveals its role in maintaining histone methylation homeostasis. Proc Natl Acad Sci USA 106: 4260-4265, 2009.
12. Bostrom P, Magnusson B, Svensson PA, Wiklund O, Borén J, Carlsson LM, Ståhlman M, Olofsson SO and Hultén LM: Hypoxia converts human macrophages into triglyceride-loaded foam cells. Arterioscler Thromb Vasc Biol 26: 1871-1876, 2006.

13. Shen GM, Zhao YZ, Chen MT, Zhang FL, Liu XL, Wang Y, Liu CZ, Yu J and Zhang JW: Hypoxia-inducible factor-1 (HIF-1) promotes LDL and VLDL uptake through inducing VLDLR under hypoxia. Biochem J 441: 675-683, 2012.

14. Wang GLand Semenza GL: Characterization of hypoxia-inducible factor 1 and regulation of DNA binding activity by hypoxia. J Biol Chem 268: 21513-21518, 1993.

15. Li X, Zhang J, Gao L, McClellan S, Finan MA, Butler TW, Owen LB, Piazza GA and Xi Y: MiR-181 mediates cell differentiation by interrupting the Lin28 and let-7 feedback circuit. Cell Death Differ 19: 378-386, 2012.

16. Pescador N, Villar D, Cifuentes D, Garcia-Rocha M, Ortiz-Barahona A, Vazquez S, Ordoñez A, Cuevas Y, Saez-Morales D, Garcia-Bermejo ML, et al: Hypoxia promotes glycogen accumulation through hypoxia inducible factor (HIF)-mediated induction of glycogen synthase 1. PLoS One 5: e9644, 2010.

17. Shen GM, Zhang FL, Liu XL and Zhang JW: Hypoxia-inducible factor 1-mediated regulation of PPP1R3C promotes glycogen accumulation in human MCF-7 cells under hypoxia. FEBS Lett 584: 4366-4372, 2010.

18. Straub BK, Herpel E, Singer S, Zimbelmann R, Breuhahn K, Macher-Goeppinger S, Warth A, Lehmann-Koch J, Longerich T, Heid $\mathrm{H}$ and Schirmacher P: Lipid droplet-associated PAT-proteins show frequent and differential expression in neoplastic steatogenesis. Mod Pathol 23: 480-492, 2010.

19. Ostler DA, Prieto VG, Reed JA, Deavers MT, Lazar AJ and Ivan D: Adipophilin expression in sebaceous tumors and other cutaneous lesions with clear cell histology: An immunohistochemical study of 117 cases. Mod Pathol 23: 567-573, 2010.

20. Wada Y, Sugiyama A, Yamamoto T, Naito M, Noguchi N, Yokoyama S, Tsujita M, Kawabe Y, Kobayashi M, Izumi A, et al: Lipid accumulation in smooth muscle cells under LDL loading is independent of LDL receptor pathway and enhanced by hypoxic conditions. Arterioscler Thromb Vasc Biol 22: 1712-1719, 2002.

21. Castellano J, Aledo R, Sendra J, Costales P, Juan-Babot O, Badimon L and Llorente-Cortés V: Hypoxia stimulates low-density lipoprotein receptor-related protein-1 expression through hypoxia-inducible factor- $1 \alpha$ in human vascular smooth muscle cells. Arterioscler Thromb Vasc Biol 31: 1411-1420, 2011.

22. Cal R, Castellano J, Revuelta-López E, Aledo R, Barriga M, Farré J, Vilahur G, Nasarre L, Hove-Madsen L, Badimon L and Llorente-Cortés V: Low-density lipoprotein receptor-related protein 1 mediates hypoxia-induced very low density lipoprotein-cholesteryl ester uptake and accumulation in cardiomyocytes. Cardiovasc Res 94: 469-479, 2012.

23. Perman JC, Boström P, Lindbom M, Lidberg U, StÅhlman M, Hägg D, Lindskog H, Scharin Täng M, Omerovic E, Mattsson Hultén L, et al: The VLDL receptor promotes lipotoxicity and increases mortality in mice following an acute myocardial infarction. J Clin Invest 121: 2625-2640, 2011.

24. Castellano J, Farré J, Fernandes J, Bayes-Genis A, Cinca J, Badimon L, Hove-Madsen L and Llorente-Cortés V: Hypoxia exacerbates $\mathrm{Ca}(2+)$-handling disturbances induced by very low density lipoproteins (VLDL) in neonatal rat cardiomyocytes. J Mol Cell Cardiol 50: 894-902, 2011

25. Gimm T, Wiese M, Teschemacher B, Deggerich A, Schödel J, Knaup KX, Hackenbeck T, Hellerbrand C, Amann K, Wiesener MS, et al: Hypoxia-inducible protein 2 is a novel lipid droplet protein and a specific target gene of hypoxia-inducible factor-1. FASEB J 24: 4443-4458, 2010. 